\title{
A EDUCAÇÃo POPULAR NOS INQUÉRITOS POLICIAIS MILITARES PÓS-1964
}

\author{
Afonso Celso Scocuglia
}

Este trabalho é parte de uma reconstrução das histórias e das memórias da ditadura e da educaçáo política pós-1964. Nele, especificamente, estâo envolvidos os dirigentes da Campanha de Educação Popular (CEPLAR) da Paraíba. Sua fonte principal foi o Inquérito Policial Militar (IPM) instaurado pelo Exército que indiciou 52 pessoas e tramitou no Superior Tribunal Militar (STM)(1964-1969), incluindo, assim, a atuaçáo dos delatores e dos responsáveis pelo processo judicial. Em termos metodológicos, este estudo entrelaçou a pesquisa bibliográfica e documental, além das fontes orais (e escritas) fornecidas pelos indiciados pelo IPM, utilizando a análise de discurso como ferramenta e procedimento. Quanto à fundamentação teórica, buscamos alicerces como a inseparabilidade passado/presente (LE GOFF, I992; BLOCH, 1987), história do tempo presente (RÉMOND, I996), vigilância e punição (FOUCAULT, I979; 1986), hegemonia e papel dos intelectuais (GRAMSCI, I982), ideologia e aparelhos do Estado (ALTHUSSER, 1980). Ademais, agregamos estudos sobre a justiça fardada (LEMOS, 2004), a tutela amistosa dos militares sobre os civis brasileiros (ZAVERUCHA, 1996), a montagem do Estado de classe (DREIFUSS, I98I), a ditadura escancarada (GASPARI, 2004) e o Estado militar (GERMANO, 1993).

Palavras-chave: Ditadura. Educação popular. História. Inquérito policial militar.
Docente do Programa de Pós-Graduação em Educação - UFPB;

Pesquisador do CNPq. Joáo Pessoa - PB [Brasil] afonso.scocuglia@pesquisador. cnpq.br 


\section{Introdução}

A educação brasileira nos anos 1950 e 1960 foi marcada pela eletricidade política dos "anos dourados" e, depois, pela ditadura militar. Protestos, passeatas, métodos ativos, professores progressistas, organização estudantil, repressão, Ato Institucional no 5 (AI-5, e o artigo 477), tortura, desaparecimentos, métodos tecnicistas, autoritarismo exacerbado, delaçóes... e tanto mais. Educação e política nunca andaram tão juntas, inseparáveis. Pode-se dizer que a vida educacional transpirava a politicidade das ruas, dos novos tempos, da possibilidade de uma nova história, da resistência ao autoritarismo, mas também da significativa adesão de professores, estudantes e dirigentes aos direcionamentos políticos impostos pelo Estado militar (GERMANO, I993) pós-I964, consubstanciados nas reformas educacionais de I968 e I97I.

$\mathrm{Na}$ Paraíba, como de resto em todo o país, o cenário educacional foi palco tanto das manifestaçóes "progressistas/de esquerda" quanto daquelas que pugnavam pela manutençáo da ordem decretada pela ditadura pós-1964. Movimentos de cultura e educação popular progressistas e conservadoras incendiaram o cenário político-educativo da época. Ademais, assim como os professores, estudantes e os políticos, os sindicalistas, jornalistas, operários, camponeses das ligas, juventude católica e outros atores políticos fizeram da década de 1960 uma das mais movimentadas e conturbadas do século XX. Não por acaso, a partir do momento que os golpistas tomaram o poder em I964, os estudantes, os professores, os políticos e todos os ativistas dessa educação política tornaram-se alvos prioritários da repressão e dos aparelhos do Estado militar. Todos sabemos que a brutalidade da ditadura recaiu sobre os "subversivos" com todas as suas armas, inclusive as "legais".

Após o golpe civil-militar de I964, as forças repressivas instauraram, em cada estado da federação, um Inquérito Policial Militar (IPM). Na Paraíba, 52 pessoas foram indiciadas e, entre 1964 e I969, submeteram-se como réus ao processo instaurado pelo IV Exército (Regiáo Nordeste), com sede em 
Recife. Tramitado, o IPM da Paraíba (IPM-PB) foi concluído em I969, encontrando-se, desde então, arquivado no Superior Tribunal Militar (STM), em Brasília. Tal IPM (Processo No 70/64, Autos Findos No I5 I/69), de 4I7 I páginas, guarda uma parte ainda náo revelada da história contada sob a ótica da justiça fardada e dos serviços de repressáo da ditadura que se apoderaram do país por longos anos.

Resquícios e indícios dessa história freqüentemente vêm à tona, seja pelo aparecimento de documentos queimados (a exemplo dos encontrados na Base Aérea de Salvador, Bahia, 2005), de fotos de prisioneiros torturados, publicadas pela imprensa (como as que supostamente mostravam, em 2005, o jornalista Vladimir Herzog, assassinado, em 1975, no cativeiro do Destacamento de Operaçóes de Informaçóes-Centro de Operaçóes de Defesa Interna [DOI-CODI] do II Exército), e de várias outras "pontas de icebergs" dessa história de arbítrios legalizados. Parte da sociedade brasileira clama por esclarecimentos e, em última instância, pela total revelação dessa parte escondida da história. Muitos familiares de desaparecidos e/ou prejudicados pelo Estado militar que foi instaurado continuam a reclamar os corpos de seus parentes e/ou informaçôes sobre desaparecidos. Concomitantemente, setores militares reagem, rebatem críticas, tentam justificar o uso institucional da força bruta diante da "guerra" que viviam contra os considerados "subversivos" e mostram, acima de tudo, que as conviç̧ôes da chamada "linha dura" das forças militares não se extinguiram; ao contrário, demonstram estar vivas e, conforme algumas insinuaçôes, prontas para agir de novo. Essa vivacidade seria produto histórico da "tutela amistosa" dos militares sobre os civis no Brasil que continuaria a existir mesmo depois de mais de duas décadas do fim do Estado militar (ZAVERUCHA, I996).

Se por um lado, estruturalmente, o autoritarismo brasileiro, na sua versão militarizada, que ao longo da República tem-se mostrado recorrente, recrudesce de tempos em tempos, demonstrando que as forças militares brasileiras, mesmo não ocupando o centro do cenário histórico-político da 
I Ver o trabalho de Zaverucha (1996) citado. atualidade, nunca deixaram os bastidores da cena brasileira e que setores mais "duros" tentam demonstrar que estão sempre prontos para intervir, por outro, tem sido visível o temor dos governos brasileiros pós-1985 em reabrir as feridas dos tempos da ditadura, postergando o acesso da sociedade aos documentos e aos arquivos que revelariam os desmandos perpetrados pelas forças repressivas. Tal fato deixa transparecer a impressão de que as elites civis temem a possibilidade de novas intromissóes militares na vida brasileira.

Se é verdade que nos últimos vinte anos a democracia política ocupou espaços importantes, também é fato que os representantes dos "anos de chumbo" e seus adeptos inscrustados nas forças armadas continuam ameaçadores e dão demonstração de que alguns de seus setores não hesitariam em quebrar a normalidade constitucional, segundo eles, "se fosse necessário". Os documentos arrolados e analisados por Lucas Figueiredo no livro Ministério do silêncio (2005) corroboram e dramatizam essa impressão. Ao contrário de países como a Espanha, o Chile e a Argentina ${ }^{\mathrm{I}}$ que, uns mais, outros menos, conseguiram que as forças civis controlassem e punissem os militares responsáveis pelo arbítrio truculento, no Brasil não encontramos nenhuma demonstração de providências desse tipo. Certamente, o pretexto de que a Anistia de I979 serviu para ambos os "lados" não consegue explicar a "tutela amistosa" instaurada. Verifica-se também que parte significativa da sociedade civil organizada, e da própria imprensa, faz questáo de "esquecer esse passado" e, visivelmente, teme que esse período retorne. Trata-se de um esforço inútil, pois, como nos ensina Le Goff (1992), o passado e o presente são inseparáveis, Mais do que isso: a regressividade metódica, defendida por Bloch (1987), nos mostra que podemos modificar o passado partindo do presente (tempo e espaço do pesquisador).

Nesse sentido, uma das oportunidades presentes para reconstruir uma parte desse passado concentra-se na investigação das peças processuais que a ditadura instalou quando acusou pessoas e entidades como subversivas à ordem constituída. Os inquéritos policiais militares realizados pela ditadura em todos os estados brasileiros são peças importantíssimas entre os documentos 
acessíveis para essa reconstrução histórica. Nesse material constata-se a fúria legalista dos golpistas no poder em procurar demonstrar e justificar as acusaçóes contra parlamentares, estudantes, professores, jornalistas, comunistas, religiosos, advogados, agricultores e políticos como "inimigos da pátria" condenáveis por suas opiniōes, escritos, trabalhos, pregações, livros e propostas. Investigar minuciosamente cada página desses inquéritos constitui poderoso instrumento de reconstrução de parte significativa dessa história encoberta, que infelicitou milhares de brasileiros e, a rigor, todo o país, durante muitos anos. O livro Justiça fardada (2004), organizado por Renato Lemos, que tem como centro a atuação do General Peri Beviláqua no Superior Tribunal Militar (STM), demonstra cabalmente tal relevância.

Com efeito, pelos motivos expostos, as pesquisas sobre os processos judiciais a que foram submetidos milhares de brasileiros após o golpe militar de 1964 tornaram-se inadiáveis e, nesse âmbito, os Inquéritos Policiais Militares realizados constituem fontes históricas de grande valia. Certamente, a investigação com base no IPM da Paraíba em foco não pode ser isolada; ao contrário, deve ser complementada e comparada com os depoimentos orais dos indiciados no processo, além de uma série de outros dados e informações colhidas na imprensa, nos arquivos públicos e privados, enfim, em todas as fontes existentes.

Neste trabalho, focaremos parte do IPM da Paraíba ao qual foram submetidos os/as dirigentes da Campanha de Educação Popular (CEPLAR). Tal campanha foi uma das pioneiras na aplicação do chamado "Método Paulo Freire" para alfabetizar milhares de jovens e adultos em várias cidades da Paraíba, a partir das duas principais sedes localizadas em João Pessoa e Campina Grande. O cenário histórico focado vai desde o contato com Paulo Freire e a equipe do "Método", no fim de I96I, até sua extinção em março de 1964, quando suas duas sedes foram invadidas pelo Exército, seus principais dirigentes detidos e, em seguida, indiciados pelo IPM (I964-I968). Os depoimentos, a seguir, trazem as representaçóes dos militares responsáveis 
2 As fontes da pesquisa serão indicadas nas notas. Ao trabalhar com esse tipo de fonte, tornou-se impossível omitir os nomes dos citados pelo IPM. No entanto, ao contrário de qualquer tipo de constrangimento público, pensamos que as citaçôes servem para homenagear as/os principais dirigentes e educadores da CEPLAR envolvidos.

3 Ophélia Amorim, Maria das Dores de Oliveira (Porto), Iveline da Costa (Lage), Maria Salete Ramos (Van der Poel), Leopoldo Lima Filho, Lígia Macedo, Natil de Castro, Adalcino de Oliveira, Josué Rodrigues e Heloísa de Albuquerque.

4 Fonte: denúncia publicada no Diário da Justiça, em I5/08/65, anexada ao IPM - Processo n. $70 / 64$, f. $3322 / 3326$, v.20/23. pelo IPM e dos dirigentes da CEPLAR vencidos pelo golpe de I964, além dos testemunhos e/ou delaçôes da suposta "subversão comunista" engendrada na Paraíba. Esta é uma parte da nossa pesquisa ${ }^{2}$, e os resultados obtidos são comunicados adiante.

\section{A educação popular no Inquérito Policial Militar da Paraíba (1964-1969)}

Nas 4.307 folhas do Inquérito Policial Militar (IPM), chamado "Processo de Subversão Geral da Paraíba (N.o 70/64)” - arquivado no Superior Tribunal Militar (STM), em Brasília, sob denominação "Autos-Findos N. o I5 I/69" -, a Campanha de Educação Popular da Paraíba (CEPLAR) e seus dez integrantes processados ${ }^{3}$ ocupam mais de 620 páginas. Tal ocorrência denota a importância que as autoridades militares encarregadas do IPM deram à CEPLAR, em relação ao quadro total da "subversão" na Paraíba.

Os militares que dirigiram os inquéritos, referentes tanto à CEPLAR quanto à CEPLAR-CG (CEPLAR de Campina Grande), pensaram ter encontrado provas materiais da "subversão" e das "ações comunistas" com a apreensão de materiais didáticos usados na alfabetização, além de questóes para testes de seleção de professores. Nesse sentido, mereceram especial atenção as "dezoito lições de conscientização", usadas no eixo João Pessoa-Sapé, e as "fichas-roteiro" para alfabetização, utilizadas em Campina Grande, já referidas. Em todas as denúncias formuladas contra os integrantes da campanha sediada na capital, a acusação centrava-se nas "dezoito liçôes", enquanto as "fichas-roteiro" constituíam a principal peça acusatória contra a diretoria da CEPLAR-CG ${ }^{4}$. Nesse aspecto, basta atentar para os termos das denúncias contra os dez indiciados (quatro de João Pessoa e seis de Campina Grande) para notar a importância dada no inquérito aos documentos citados. $\mathrm{Na}$ denúncia contra Maria das Dores Oliveira, dirigente da CEPLAR, por exemplo, 
lê-se: "[...] integrava como confessou no seu depoimento de fl.3r3, a equipe[...] responsável que era pela elaboração de I8 lições de conscientização de conteúdo subversivo (fls.32 e 42, 302, 313)" (IPM - Processo n. 70/64, f. 3322/3326, v.20/23).

Por sua vez, Josué Rodrigues de Souza, presidente da CEPLAR-CG, foi denunciado porque participou da "equipe responsável pela elaboraçáo das fichas-roteiro de caráter subversivo (politização) - anexo No I, fls. I52 a I55. Era um subversivo, atuante e solerte" (IPM - Processo n. 70/64, f. 3322/3326, v.20/23). Nos outros três indiciamentos dos dirigentes de Joáo Pessoa e nos cinco de Campina Grande, as "dezoito liçóes de conscientização" e as "fichasroteiro" constituíram, respectivamente, o que "de mais subversivo" os militares encontraram no material usado pelas duas CEPLARs.

Logo após o golpe, as sedes das duas entidades foram invadidas por militares. O documento "Auto de Busca e Apreensão" relata a invasão e o confisco de todo o material presente na sede da CEPLAR:

Aos três dias do mês de abril do ano de mil novecentos e sessenta e quatro, nesta cidade de João Pessoa, em cumprimento de ordem expressa do Senhor Coronel Comandante da Guarnição de apreender todo e qualquer documento ou publicação de caráter subversivo ou propaganda do regime comunista, nos dirigimos à Praça D. Adauto, onde está sediada a Campanha de Educação Popular (CEPLAR) (e) procedemos a mais minuciosa busca. (IPM, Processo n. $70 / 64$, v. I/23, f. I7).

Entre o material apreendido, os militares responsáveis destacaram o que consideravam "provas" das vinculaçōes comunistas da campanha. Nesse sentido, relacionaram, no IPM, os textos e os livros mais "comprometedores", a exemplo de: "Constitucion de la Union das Repúblicas Socialistas Soviéticas"; "Viva el leninismo"; "ABC do comunismo"; "Cuba - ilha explosiva"; "A edu- 
5 Fonte: IPM - Processo n. 70/64, "Auto de busca e apreensão", v. I/23, f.I7/I9.

6 Fonte: IPM - Processo n. $70 / 64$, v.7/23, f.616/617.

7 Fonte: IPM - Processo n. $70 / 64, v .7 / 23, f .645$. cação na URSS"; "Discurso de Luís Carlos Prestes"; "Desenvolvimento do comunismo moderno"; "Proletários de todos os países, unamo-nos para lutar contra nosso inimigo comum"; "Discursos del doctor Fidel Castro Ruiz"; "Em marcha para o IV Congresso do PCB"

Náo se dispóe de informaçóes precisas acerca do uso dos livros e textos encontrados na CEPLAR. Todos os depoimentos apontam um vigoroso movimento intelectual e cultural, tendo como núcleo a sede de João Pessoa. Partindo-se da idéia de que os textos e livros estavam lá para serem lidos, discutidos, disseminados, pode-se deduzir que o "comunismo" da CEPLAR ia além dos constantes conflitos entre seus integrantes e se teria constituído numa sólida influência teórica e prática (no sentido da exemplificação positiva dos casos de Cuba e da URSS).

No andamento do processo, foram tomados os depoimentos dos indiciados. As informaçóes desses depoimentos estão contidas nos vários documentos, denominados "Termos de Perguntas ao Indiciado" (TPIs). Acompanhando-se esses TPIs, tem-se a nítida percepção de sua logicidade, que consistia, basicamente, em relacionar a participação do acusado na "subversão", reconstituir "fatos incriminadores" e apontar suas açóes e as de seus parceiros. No TPI de João Alfredo Guimarães, por exemplo, é informado o destino das verbas repassadas pelo MEC (primeira parcela de $\mathrm{Cr} \$ 20$ milhóes) e outros $\mathrm{Cr} \$ 20$ milhóes que ficaram retidos no Banco do Brasil quando eclodiu o golpe. Há também informaçóes sobre as despesas da CEPLAR (algumas discriminadas) e a indicação dos integrantes do Departamento de Educação Fundamental, que foram responsáveis pela elaboração das "dezoito liçôes de conscientização", das quais quatro foram denunciadas posteriormente ${ }^{6}$. Já o TPI de Heloísa Helena de Albuquerque acusava-a de participante da elaboração de questóes para o "Teste de seleção de professores", considerado como “inquisição ideológica”. Por sua vez, o TPI de José Rodrigues Lustosa, presidente da CEPLAR - próximo ao governador Gondim, assim como os outros dois presidentes -, entre novembro de 1961 e 29 de abril de 1963, trouxe as 
motivaçôes das divergências que o levaram a renunciar. Citando um dos exemplos que mostravam, segundo ele, a usurpação de sua autoridade de presidente por membros do Departamento de Educação Fundamental, Lustosa comenta o fato de ter encontrado Paulo Pontes, (do Partido Comunista Brasileiro [PCB]), como um dos diretores da entidade. No processo, lê-se:

Perguntado qual o fato que determinou de forma imediata a sua renúncia, respondeu que foi o da comunicação de estar PAULO PONTES na direção da Divisão de Arte e Teatro (Divulgação), feita por Maria das Dores Oliveira quando do regresso do depoente de suas férias. ${ }^{8}$

No depoimento de Iveline Lucena da Costa (Lage), uma das questóes que mais chamaram a atenção dos interrogadores foi a retirada de documentos da sede da CEPLAR, dias antes do golpe, e sua transferência para a casa de seu irmáo, além de documentos da Frente de Mobilização Popular (FMP) encontrados na sede. Segundo a dirigente, os documentos foram retirados "[...] com receio de que outras pessoas menos avisadas e mais apaixonadas interpretassem-nos como subversivos, inutilizando o seu trabalho e de seus companheiros." "O clima de conflito já indicava para essa dirigente da CEPLAR, ao contrário dos que náo acreditavam no golpe, a possibilidade de um desfecho no qual a campanha fosse taxada de "subversiva" e de que os documentos retirados servissem de "prova" incriminatória, como realmente ocorreu. Uma das acusaçôes, a da possibilidade de "doutrinação", foi, em parte, confirmada por uma das líderes da CEPLAR, Lígia das Mercês Macedo. No seu TPI, pode-se ler:

Perguntado se admite que o método PAULO FREIRE poderia servir de veículo, convenientemente distorcido, para doutrinação ideológica, respondeu afirmativamente, ressaltando, todavia,
8 Fonte: IPM - Processo n. $70 / 64$, v. $7 / 23$, f. 647 .

9 Fonte: IPM - Processo n. $70 / 64$, v. $4 / 23$, f. 303 . 
Io Fonte: IPM - Processo n. $70 / 64$, v. $4 / 23$, f. 3 II.

II Fonte: IPM - Processo n. $70 / 64$, v. $4 / 23$, f. $305 / 308$.

I2 Esse departamento foi dirigido por Paulo Pontes que, posteriormente, destacou-se nacionalmente como um dos teatrólogos brasileiros de vanguarda, ao lado de Vianinha, Gianfrancesco Guarnieri e outros.

I3 Fonte: IPM - Processo n. $70 / 64$, v. $4 / 23$, f. 358 . que tal procedimento, pela própria organização da entidade, só poderia ser levado a efeito com a conivência ou orientação do Departamento de Educação Fundamental e da própria direção da CEPLAR. ${ }^{\circ}$

No entanto, o mais longo dos TPIs foi o de Juarez Macedo ${ }^{11}$. As perguntas ao indiciado, além de livrá-lo da denúncia processual, serviram muito mais de tentativa de corroborar a incriminaçáo dos principais líderes do Departamento de Educaçáo Fundamental do que esclarecer a sua participação. Segundo seu depoimento, dirigentes desse departamento solapavam sua autoridade de presidente, na elaboraçáo de materiais pedagógicos da alfabetização. Além disso, havia as ações político-culturais do Departamento de Arte e Divulgação ${ }^{\mathrm{I2}}$ que, a seu ver, não cumpriam os objetivos para os quais a CEPLAR havia sido criada, ou seja, a alfabetização de adultos. No dia 24 de abril de 1964, Macedo endereçou um memorial ao Major Aquino, responsável pelas investigaçóes. Em relação à seleção de professores (coordenadores de debates), por exemplo, o ex-presidente da CEPLAR denunciava:

A vigilância do entáo presidente, notadamente a respeito do trato da instituição com o público, do que é exemplo a inscrição de candidatos ao teste para monitor e mesmo a apresentação do teste, era havida por ingerência ou imiscuição nos assuntos da alçada do Departamento de Educação Fundamental. Em conseqüência, foi difícil o acesso às fichas de inscrição de candidatos e mesmo às reunióes onde se discutia a feitura dos mesmos, dos referidos testes [...] Recorda-se em particular, dentre as várias objeções levantadas pelo presidente, que o teste proposto se constituía numa espécie de inquisição ideológica, de todo incompatível com o espírito do presidente e dos próprios Estatutos. ${ }^{\mathrm{I3}}$ 
Ao atacar seus parceiros da CEPLAR, Macedo queria, sobretudo, defender-se, para não ser denunciado e processado. Já a campanha, por sua vez, não passou ilesa nesse processo, sendo acusada por uma ex-integrante de seus quadros (coordenadora). As declarações de Edeltrudes Balduíno da Cunha foram as que mais pesaram contra a CEPLAR, conforme evidencia o Termo de Inquirição de Testemunha (TIT), assinado pela acusadora:

A sede da CEPLAR vivia sempre cheia de pessoas a discutir reformas de base e eclosão de greves, sendo grande parte constituída de estudantes. Sabe a depoente que, encabeçada pelo 'cérebro' da CEPLAR, estava sendo articulada uma greve geral de protesto pela atuação do Coronel Luiz de Barros na regiáo Mari-Sapé. Essa greve estava sendo estudada e preparada para eclodir entre estudantes, operários das fábricas de Bayeux e seria reforçada por passeatas e concentraçóes de camponeses do Estado e transportados de Pernambuco. A depoente declara que reinava uma certa euforia entre os dirigentes da CEPLAR pelos resultados já atingidos pela sua 'conscientização', especialmente baseados nas experiências do setor de agitação, por ocasião dos 'quebra-quebra' levados a cabo na Polícia de Menores [...] e no caso do aumento das passagens de ônibus. ${ }^{14}$

Embora essa testemunha de acusação conhecesse a CEPLAR, a articulaçáo das frases no texto pode sugerir ao leitor que ele poderia ter sido montado como peça-chave da acusação pelos próprios encarregados de transcrever o depoimento. Nesse sentido, uma das tentativas visíveis foi vincular as açóes da CEPLAR aos movimentos em prol de uma aliança "estudantil-operária-camponesa" da qual algumas dirigentes da campanha seriam os "cérebros". Isso fica claro no mesmo depoimento prestado pela ex-coordenadora de debates da campanha:
I4 Fonte: IPM - Processo n. $70 / 64$, v. $4 / 23$, f. 346 . 
I5 Fonte: IPM - Processo n. $70 / 64$, v. $4 / 23$, f. 346 .

I6 Fonte: IPM - Processo n. $70 / 64$, v. $4 / 23$, f. 347 .

I7 No IPM em foco as integrantes da CEPLAR ligadas ao governo estadual não foram indiciadas. Segundo o depoimento de João Alfredo Guimarães, antes citado, havia uma preocupação dos militares encarregados do processo em isentar o governador, que aderiu aos golpistas em abril 1964 .
Era norma nas aulas de conscientização dadas pelas moças (dirigentes do Departamento de Educação Fundamental) recomendar aos alunos que procurassem sempre despertar nos humildes o sentimento de que estavam sendo explorados e humilhados, por exemplo: quando puderem conversar com um soldado, procurem mostrar-lhe que o Coronel vive bem, come bem, veste bem, e o soldado está sempre servindo, se humilhando, se enquadrando, sendo punido e vive mal vestido e mal alimentado; quando falarem a um camponês, digam-lhe para que não tenham tanto medo do Exército e da Polícia, que experimentem enfrentá-los e verão que os soldados não atirarão nos seus irmãos pobres e humildes. ${ }^{15}$

Na seqüência, a mesma testemunha denunciava um curso sobre uma “[...]revolução para acabar com a espoliação americana e com os privilégios [...]", tendo como base o "[...] poder representado pelo CGT, a força latente das massas camponesas arregimentadas e a colaboração decisiva dos soldados,

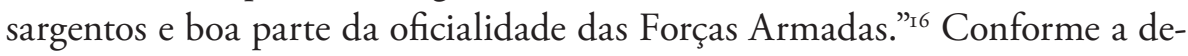
nunciante, era comum a exaltação do comunismo, de Cuba e da União das Repúblicas Socialistas Soviéticas (URSS), nos cursos da CEPLAR. No entanto, surpreendentemente, num segundo depoimento, a ex-coordenadora quase descaracterizou suas acusações, com respostas evasivas e alegação de "falta de memória”. Essa descaracterização fez com que as acusaçóes se concentrassem nas "dezoito liçôes de conscientização" e nas "fichas-roteiro" e justificassem o depoimento do último presidente da CEPLAR. Segundo ele, havia preocupação da direção do IPM em não enquadrar, por exemplo, o governo do Estado e a Arquidiocese, o que pode ter colaborado para amainar as incisivas declarações iniciais dessa testemunha de acusação ${ }^{17}$.

Por seu turno, o andamento do IPM específico sobre a CEPLAR-CG, quase todo concentrado nas 187 folhas do volume I8/23 do Processo em foco, tentava enquadrar a diretoria da campanha, por meio de depoimentos de vin- 
te coordenadores e supervisores que atuaram em Campina Grande, como se pode observar nos seus respectivos TITs. Uma das coordenadoras, Herta Meira, disse que "[...] nunca notou nenhuma tentativa de subversão por parte dos seus dirigentes. ${ }^{{ }^{\prime}{ }^{8}}$ No testemunho de Merilande de Araújo, supervisora, lê-se: "[...] o que fazíamos era apenas esclarecer o povo" e "[...] sob o ponto de vista subversivo nada tem a declarar [...]"19. Rita Vieira, supervisora, informou à autoridade militar que "[...] havia aulas em que, no momento da politização, muitos alunos dormiam e na parte de alfabetização o interesse era quase integral" ${ }^{\prime 20}$. Outra testemunha, Sulamita Ithamar, coordenadora, disse que "[...] ensinou no bairro Catolé, o pessoal desse bairro desinteressou-se pela politi-

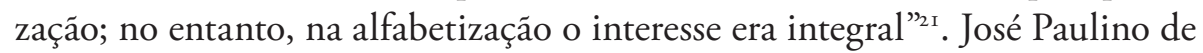
Oliveira, coordenador, declarou que "[...] na parte de politização havia uma norma taxativa proibindo o coordenador [...] de externar a opiniáo pessoal", e que o "Professor Josué" sempre teve posição de realce nas reuniōes ${ }^{22}$ realizadas na Sala dos Acólitos (Igreja/Catedral).

Embora o objetivo dos responsáveis pelo IPM fosse usar esses depoimentos contra os dirigentes da CEPLAR-CG, as informaçóes contidas nas inquiriçôes das testemunhas nada acrescentaram ao que já existia nos autos. Assim, à semelhança da CEPLAR (e das suas "I8 liçóes de conscientizaçáo"), o inquérito foi conduzido para que os autores das "fichas-roteiro" de politização, usadas nos cinqüenta e cinco núcleos de Campina Grande, fossem denunciados.

Náo se pode deixar de registrar os Termos de Perguntas ao Indiciado (TPIs), referentes aos depoimentos dos membros da diretoria da CEPLARCG. O de Josué Rodrigues, por exemplo, serviu para identificar diretores, coordenadores e supervisores da campanha, além de informar os autores dos diversos textos apreendidos durante a invasáo das salas que a CEPLAR-CG ocupava na prefeitura, nos primeiros dias de abril de 1964 . Os títulos/temas desses textos indicavam seus respectivos conteúdos e a intencionalidade política dos diretores da campanha ao trabalhá-los:

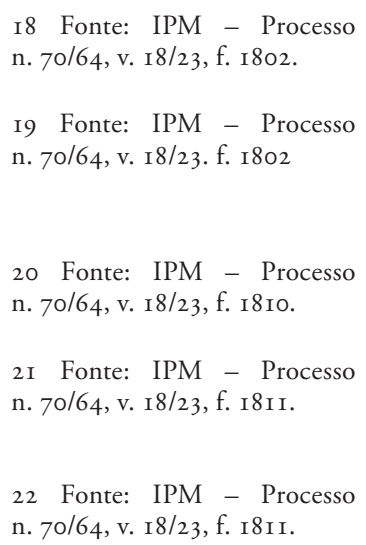


23 Todos esses textos fazem parte do v. I 8 do Inquérito Policial Militar em foco.

24 Fonte: IPM citado, v.18/23, f. I8I3-I8I6.

25 Fonte: IPM citado, v.18/23, f. 1823 .
"Método Paulo Freire"; "A revolução brasileira"; "Reforma agrária"; "As reformas de base"; "O capital estrangeiro"; "Capacidade para o desenvolvimento - Nacionalismo"; "Raízes do subdesenvolvimento"; "Os dois grandes blocos econômicos"; "Fundamentação do sistema Paulo Freire de educação" ${ }^{23}$.

Em outra passagem do seu TPI, ao ser perguntado se havia na Campanha alguma pessoa com tendência comunista, apesar de ser do PCB, Rodrigues respondeu negativamente ${ }^{24}$. Uma das diferenças entre os TPIs dos dirigentes das duas CEPLARs estava numa maior dissimulaçáo por parte dos campinenses, além da constante atribuiçáo da possível "subversão" ao papel exercido pelo coordenador. Em vários depoimentos aparecem declaraçôes semelhantes à expressa por Adalcino Queiroz, membro da diretoria:

Os supervisores eram responsáveis pela linha de conduta a que se destinava a CEPLAR, pois se algum ou alguns (coordenadores) procurassem desvirtuar o ensino com a implantação de alguma idéia subversiva, seria dado conhecimento à direção e em conseqüência seriam tomadas as devidas providências. ${ }^{25}$

Como se vê, entre evasivas e dissimulaçóes, tanto os dirigentes da CEPLAR-CG quanto seus coordenadores e supervisores não colaboraram com os responsáveis pelo IPM, restando como "prova" as "fichas-roteiro" da alfabetização. Não obstante, o comandante do Batalhão do Exército sediado em Campina Grande, ao encaminhar os resultados das investigações do IPM para o IV Exército (7 ${ }^{\circ}$ Região Militar, sede - Recife), escreveu:

Todas as fichas-roteiro que contêm palavras geradoras, apresentam caráter subversivo, dependendo da orientação dada pelo coordenador; aliás, todos os indiciados e demais coordenadores confirmam tal assertiva, exceto o professor Josué Rodrigues de Souza. 
Conclui-se, pois, que o objetivo da CEPLAR era mais de politização subversiva que propriamente alfabetização; uma vez alcançado o objetivo principal, que era o de permitir ao aluno possibilidades de conseguir o título eleitoral, estava ele suficientemente "conscientizado" e politizado para ser um instrumento de execução dos desígnios subversivos previstos na trama política delineada pelo governo passado. ${ }^{26}$

No transcorrer do IPM, os membros das CEPLARs, assim como os demais denunciados, foram enquadrados pelo mesmo motivo: "atividades comunistas". Uma das dirigentes da CEPLAR-CG destaca a impossibilidade, durante os interrogatórios, de convencer os militares de que a maioria era militante da Ação Popular (AP) que surgiu da Juventude Universitária Comunista (JUC) e que tinha até receio de trabalhar com comunistas. Para os militares, tudo o que fosse "subversivo" tinha a influência do PCB. O melhor exemplo é a denuncia oferecida:

O comunismo era o leit motiv dessa grande rede de maldade, em reação da qual é exigida, agora, a punição dos responsáveis que incitavam o povo à luta de classes com greves ou com ligas camponesas, com comícios ou com a ignominiosa "conscientização" dos escolares, dos responsáveis que degradavam o Estado com tudo isso que se chama subversão. ${ }^{27}$

No entanto, transcorridos mais de quatro anos do processo, entre a parte inicial em João Pessoa e Campina Grande, e seu posterior encaminhamento para o Superior Tribunal Militar, o final veio com a concessão de habeas corpus, por unanimidade dos votos dos Ministros, em II/9/I968. Assinado pelo então presidente do STM (Olympio Mourão Filho), seu preâmbulo ditava:
26 Fonte: IPM citado, v.18/23, f. I66I.

27 Fonte: IPM citado, v. 20/23, f. 3223. Denúncia do Promotor Militar (Othon Fialho de Oliveira), publicada no Diário da Justiça, de $15 / 8 / 65$. 
28 Fonte: IPM citado, v. $3 / 23, \mathrm{f}$. $4306 / 4307$.

29 Atualmente, nossa pesquisa (CNPq/PQ) faz o entrelaçamento comparativo das fontes escritas com os depoimentos orais dos indiciados no IPM.
Denúncia da qual já foram excluídos vários acusados, em número superior à metade e que, em relação aos demais, mantém a mesma indeterminação, o mesmo tom genérico e impreciso das imputaçôes já rejeitadas, não se demonstra apta a produzir os efeitos jurídicos a que se propôs. Habeas Corpus concedido, por inépcia da denúncia. ${ }^{28}$

Uma história que começou em I96I, foi bruscamente interrompida em I964 e, para os dirigentes das CEPLAR indiciados, continuou em forma de pesadelo até 1968/1969. Para alguns deles, no entanto, o pesadelo ainda náo saiu da memória, como atestam os depoimentos orais ${ }^{29}$.

\section{Consideraçóes finais}

De posse desses dados, documentos e depoimentos presentes no IPM, quais reflexóes poderíamos entabular a respeito dos acontecimentos e das representaçóes narrados/as?

A princípio, podemos constatar que, desde a instituição de um real poder "moderador", herdado do Império, as forças militares consubstanciaram uma "tutela amistosa" (ZAVERUCHA, I996) sobre as forças civis, seja explicitamente, por meio de intervençóes diretas, seja pela tutela amistosa ou pela presença determinante do serviço secreto militarizado (FIGUEIREDO, 2005), ou ainda pela instituição da "justiça fardada" (LEMOS, 2004) patrocinada pelo Superior Tribunal Militar (STM), e tornaram-se notórios e determinantes os movimentos de vigilância e punição (FOUCAULT, I986) sobre os indivíduos e os grupos sociais internos.

No entanto, há uma enorme diferença entre as várias intervenções, o "golpe de classe" de I964 (Dreifuss, I98I) e a instituição concreta (e imaginária, diria Castoriadis, I982) do Estado Militar entre I964 e 1985. Para 
além das quarteladas que caracterizaram as outras intervençóes diretas - e embora se argumente que os militares "moderados" seguidores do General Castelo Branco queriam devolver o poder aos civis depois do "saneamento da subversão", ao contrário dos "duros" que bancaram e tornaram a tortura um instrumento do Estado contra os inimigos -, a intervenção de 1964 foi planejada como política estatal hegemônica e duradoura. E como toda hegemonia, para ser duradoura, necessitava convencer a sociedade dos seus propósitos (GRAMSCI, I982) e criar seus próprios discursos e seus intelectuais orgânicos. Em outras palavras, precisava legitimar-se no exercício do poder.

E, nesse sentido, a "justiça fardada" exercida pelo STM na realização dos IPMs, entre 1964 e 1969, foi especialmente importante. Tratava-se de, mesmo arbitrariamente, demonstrar à sociedade a legitimidade e o senso de justiça presentes na exemplar punição dos inimigos subversivos contra os delitos e formadores de opiniáo, a exemplo dos estudantes, dos professores, dos políticos e também dos religiosos, dos sindicalistas, dos advogados, dos jornalistas etc. Nesse contexto, se, por um lado, aplicava-se a fortaleza da lei contra os inimigos, por outro tolerava-se a permissividade das açóes dos colaboradores, tantas vezes ilegais e arbitrárias, mesmo aquelas com fortes indícios de violência moral e física.

Nessa construção, a burocratização e a militarizaçáo planejadas do Estado por meio dos construtos institucionais minados por instituiçóes como o Instituto de Pesquisa e Estudos Sociais (IPES )e o Instituto Brasileiro de Ação Democrática (IBAD), das quais intelectuais orgânicos civis e militares faziam parte, estão hoje demonstradas por farta documentação e análise histórica das teses de Dreifuss (198I) e Souza (198I) às pesquisas histórico-jornalísticas de Lemos (2004), Figueiredo (2004) e de Gaspari (2004), relativas às várias fases da ditadura. Nestes trabalhos, encontram-se explícitos os meandros do poder civil-militar, as brutalidades da repressão, o desenvolvimento dos serviços secretos, as ferrenhas disputas entre os "duros" e os "moderados", a tortura sistemática como instrumento do Estado, as conexões com outros 
países da América do Sul, a proximidade com os norte-americanos, o desenvolvimento da Doutrina de Segurança Nacional etc.

Podemos constatar que o período do Estado militarizado, de 1964 a I985, tem sido um dos mais estudados e, certamente, a abundância de fontes próprias da história do tempo presente tem grande responsabilidade nesse sentido. No entanto, a importância estratégica da legitimação e da legalização das açóes repressivas do Estado militar não tem sido contemplada na mesma proporção, e podemos afirmar que o papel do STM e seus instrumentos legais, os IPMs, têm sido pouco focados. A “justiça fardada” (LEMOS, 2004) desempenhou papel decisivo tanto na normatizaçáo punitiva quanto no balizamento do que "era subversivo", do que podiam ou não os adversários do regime, ou seja, na vigilância dos supostos delitos. Importante argumentar com Lemos que:

[...] a Justiça Militar, da qual o Superior Tribunal Militar é o órgão máximo, teve a sua inserção no processo político desse período em uma tríplice condição. Como parte do Judiciário, foi órgão complementar do aparato de coerção política e instrumento auxiliar na estratégia de legitimaçấo do regime. Como parte do campo militar, foi arena de confronto entre correntes divergentes quanto aos rumos do processo político (LEMOS, 2004, p. 29).

Ademais, sua competência foi estendida aos civis considerados "subversivos", entre os quais, como alvos e réus destacados, encontramos os professores e os estudantes. Entre os próprios juízes do STM, existiram notórias divergências, destacando-se as posiçóes do General Peri Bevilaqua que, durante sua atuação (1965-1969), denunciou arbítrios e irregularidades quanto à "[...]instrumentalização política dos IPMs (a bolchevização da justiça) [...]” e o “[...] risco de transformar-se o país em um imenso quartel, caso não fosse restabelecida a ordem civil [...]” (LEMOS, 
2004, p.3I). Certamente, a militarização da justiça focada neste projeto de pesquisa constituiu um dos principais alicerces da instituição do Estado militar no pós-golpe de 1964, confirmando-se a tese do golpe de classe (DREIFUSS, I98I), da formação de um novo bloco histórico hegemônico que, por meio dos seus aparelhos de Estado (incluso o educacional), pretendia não só "limpar" a sociedade dos considerados subversivos, mas também disseminar seu poder por todos os poros e capilares (FOUCAULT, I979) da sociedade brasileira, de maneira "legítima" e duradoura. Para isso, a vigilância e a punição (FOUCAULT, I986) deveriam ser exemplares instrumentos do exercício da lei e da ordem por meio da justiça fardada. Nesse processo instituinte, o STM chegou ao requinte de punir um dos seus próprios membros quando o General Bevilaqua foi afastado com base no AI-5 (LEMOS, 2004).

Por seu turno, para os professores, estudantes, políticos, advogados, jornalistas e outros acusados representou a própria submissão de um período de suas vidas aos arbítrios da ditadura. Os visíveis traumas que alguns carregam até hoje, e evidenciam em depoimentos, corroboram a tese de que os IPMs representaram o próprio exercício prático da vigilância e da punição legalizadas que intimidaram e minaram as práticas escolares e as assemelharam às clausuras das prisóes e dos manicômios, estudados por Foucault (I986).

Sabemos que um dos alvos privilegiados pelos IPMs foram as práticas estudantis e docentes, e aqui também podemos lembrar Althusser e seu destaque aos aparelhos ideológicos do Estado e, entre os quais o escolar/educacional. $\mathrm{O}$ fato determinante de a ditadura interferir no sistema educacional como uma prioridade da sua dominação não está mais em discussão, pois tornou-se evidente (GERMANO, I993). No entanto, precisamos entender como os instrumentos legais da ditadura interferiram nesse caminho, vigiando, punindo e aparelhando o sistema na disseminação ideologia e de sua hegemonia. Para isso, as teses de Foucault (I979 e I986), Gramsci (I982) e Althusser (I980), somadas às pesquisas brasileiras 
antes mencionadas (e a outras que emergiram no desenvolvimento da pesquisa), têm sido de extrema valia. Vigilância e punição, hegemonia e papéis dos intelectuais, ideologia e aparelhos do Estado, somados aos estudos da “justiça fardada” (LEMOS, 2004), da "tutela amistosa” (ZAVERUCHA, I996) dos militares sobre os civis brasileiros, da montagem do "Estado de classe" (DREIFUSS, I98I), da ditadura escancarada, envergonhada e derrotada (GASPARI, 2004), além dos estudos sobre as interferências e conseqüências educacionais (para as instituiçôes e seus protagonistas docentes e discentes) do Estado militar (GERMANO, I993), serão decisivos para respaldar as análises da documentação relativa ao IPM e dos depoimentos orais dos réus desse inquérito.

Por outro lado, o fato de utilizarmos, como referência, a Paraíba também demonstra como o discurso dos órgãos repressivos da ditadura, por meio dos IPMs, foi determinante na desmontagem de um quadro político antes marcado pelos avanços da educação politizada, nas organizaçóes das Ligas Camponesas, no movimento político-cultural intenso, na participação decisiva da imprensa, na organização sindical, entre outros. Seria coincidência, por exemplo, o arrefecimento da resistência à ditadura coincidir com o encerramento do IPM (I969), a edição do AI-5 e a concretização das reformas educacionais (universitária e de primeiro e segundo graus) marcadas, principalmente, pela vigilância e punição de docentes e discentes? Certamente, não.

A inequívoca demonstração da importância que a "justiça fardada" deu aos "educadores subversivos" e às suas açóes está demonstrada no fato de pelo menos $20 \%$ das mais de quatro mil páginas do IPM que estamos analisando focarem a "subversão educacional". Em outras palavras, o Estado militar brasileiro demonstrou, cabalmente, quanto temia a educação politizada e seus agentes, intencionando julgá-los, puni-los exemplarmente e ocupar seus espaços hegemônicos. 


\section{THE POPULAR EDUCATION IN THE MILITARY POLICE INQUESTS AFTER-1964}

This work is part of a reconstruction of histories and memories from the dictatorship and the political education after-1964. In it, specifically, the controllers of the Campaign of Popular Education (CEPLAR) of the Paraíba State are involved. Its principal source was Military Police Inquest (IPM) restored by the Army, that accused 52 people and moved in Superior Military Court (STM) (1964-1969) and, thus, it is also included the performance of the delators and responsible for the action at law. In terms of methodology, in this study it is linked bibliographical research to documentary research and, beyond the verbal sources (and writings) supplied by the defendants by IPM, and it is used the speech analysis as a tool and a procedure. About the theoretical recital, it was searched foundations as past/present inseparability (LE GOFF, 1992; BLOCH, 1987), history of the present time (REMOND, I996), monitoring and punishment (FOUCAULT, 1979; 1986), hegemony and intellectuals role (GRAMSCI, 1982), ideology and State's devices (ALTHUSSER, 1980). Furthermore, we added studies on military justice (LEMOS, 2004), the friendly guardianship of the military on the Brazilian civilians (ZAVERUCHA, 1996), the assembly of the State of class (DREIFUSS, 198I), the manifest dictatorship (GASPARI, 2004) and the military State (GERMANO, 1993).

KeY wORDs: Dictatorship. History. Military police inquest.

Popular education.

\section{Referências}

ALTHUSSER, L. Ideologia e aparelhos ideológicos do Estado. I. ed. São Paulo: Martins

Fontes, 1980.

BLOCH, M. Introducción a la historia. I. ed. México: Fondo de Cultura Económica, 1987.

CASTORIADIS, C. A instituição imaginária da sociedade. I. ed. Rio de Janeiro: Paz e

Terra, I982. 
D'ARAÚJO, M. C. et al. Visóes do golpe-A memória militar sobre 1964. Rio de Janeiro: Relume-Dumará, I994.

. et al. Os anos de chumbo - a memória militar sobre a repressão. Rio de Janeiro:

Relume-Dumará, I994.

DREIFUSS, R. 1964: a conquista do Estado. I. ed. Petrópolis: Vozes, 198I.

FERRO, M.. A história vigiada. Rio de Janeiro: Martins Fontes, I989.

FIGUEIREDO, L. Ministério do silêncio. I. ed. Rio de Janeiro/Sáo Paulo: Record, 2005.

FOUCAULT, M. Microfísica do poder. I. ed. Rio de Janeiro: Graal, I979.

. Vigiar e punir. I. ed. Rio de Janeiro: Martins Fontes, I986.

GASPARI, E. A ditadura envergonhada. I. ed. Rio de Janeiro: Companhia das Letras, 2004.

GERMANO, J. W. Estado militar e educação no Brasil (1964-1985). I. ed. São Paulo: Cortez/EdUnicamp, 1993.

GRAMSCI, A. Os intelectuais e a organização da cultura. I. ed. Rio de Janeiro: Civilização Brasileira, 1982.

INQUÉRITO POLICIAL MILITAR. PARAÍBA. PROCESSO No 70/64. 23 Volumes, 4I7I páginas.

LE GOFF, J. História e memória. I. ed. Campinas: Editora da Unicamp, 1992.

LEMOS, R. Justiça fardada - O General Peri Bevilaqua no Superior Tribunal Militar (1965-1969). I. ed. Rio de Janeiro: Bom Texto, 2004.

SOUZA, M. I. de. Os empresários e a educação - O IPES e a politica educacional após 1964. I. ed. Petrópolis: Vozes, I98I.

AUTOS FINDOS No I5I/69. SUPERIOR TRIBUNAL MILITAR (STM)

ZAVERUCHA, J. Rumor de sabres. I. ed.I Rio de Janeiro: Relume-Dumará, 1996.

Recebido em 5 maio 2007 / aprovado em Is jun. 2007.

\section{Para referenciar este texto}

SCOCUGLIA, A. C. A educação popular nos inquéritos policiais militares pós-1964. EccoS, São Paulo, v. 9, n. I, p. 17-38, jan./jun. 2007. 